\title{
O ético e o estético no ensino de literatura: o sujeito e sua experiência
}

\author{
The ethical and aesthetical in Literature teaching: \\ the relevance of the subject and his/her "reading" of world
}

\author{
Everton Almeida Barbosa ${ }^{*}$ \\ Universidade do Estado de Mato Grosso \\ Tangará da Serra, MT, Brasil \\ Marta Helena Cocco** \\ Universidade do Estado de Mato Grosso \\ Tangará da Serra, MT, Brasil
}

\begin{abstract}
Resumo: Neste artigo reunimos reflexões sobre o ensino de literatura, enfatizando a percepção do mundo como aspecto importante na preparação para a leitura da palavra. Essa proposição tem o intuito de oferecer um complemento aos estudos e pesquisas centradas no aluno/leitor e em sua relação direta com o texto, direcionando as reflexões para a relação eu/outro e para a figura do professor. $O$ artigo consiste em uma discussão teórica, baseada em relatos de experiência de Paulo Freire (1989) e Tzvetan Todorov (2006). Partindo da afirmação de Freire de que a leitura de mundo vem antes da leitura da palavra, procuramos definir o status das atividades ética e estética, a partir de Mikhail Bakhtin (2006), mostrando os limites entre elas e como essa reflexão pode auxiliar no ensino de leitura do texto literário. Em outra via, a partir dos relatos de Freire e Todorov, propomos uma reflexão sobre o conceito de "experiência", segundo Walter Benjamin (1994) e Jorge Larrosa (2014), no intuito de evidenciar a necessidade de afirmação do sujeito autor/leitor/professor.
\end{abstract}

Palavras-chave: Ensino de literatura. Ética. Estética. Sujeito. Experiência.

\begin{abstract}
In this paper, we gather reflections on teaching of literature, emphasizing the perception of the world as an important aspect in the preparation for the reading of word. This proposition aims to offer a counterpart to studies and researches centered on the student/reader and its straight relation with the text, directing the reflections towards the self/other relation and the professor's image. The article consists of a theoretical discussion, based on experience reports by Paulo Freire (1989) and Tzvetan Todorov (2006). Starting from Freire's statement that the reading of world comes before the reading of word, we seek to define the status of ethical and aesthetic activities, following Mikhail Bakhtin (2006), showing the limits between them and how this reflection can help in teaching the reading of literary text. In another way, from the reports of Freire and Todorov, we propose a reflection on the concept of "experience", according to Walter Benjamin (1994) and Jorge Larrosa (2014), in order to highlight the need for affirmation of the subject as author/reader/teacher.
\end{abstract}

Keywords: Literature teaching. Ethic. Aesthetics. Subject. Experience.

*Doutorado em Estudos Literários pela UFMG, professor de Literaturas de Língua Portuguesa na UNEMAT - campus de Tangará da Serra/MT e do Mestrado Profissional PROFLetras - Cáceres/MT, pesquisador do Grupo de Pesquisa LER - Literatura, Leitura e Ensino (UNEMAT), coordenador do projeto de extensão Corpo \& Cordas (UNEMAT).E-mail: everton@unemat.br.

**Doutora em Letras e Linguística pela UFG, professora de Literaturas de Língua Portuguesa na UNEMAT - campus de Tangará da Serra/MT e do Mestrado Profissional PROFLetras - Sinop/MT, líder do Grupo de Pesquisa LER - Literatura, Leitura e Ensino (UNEMAT). E-mail: coccomartahelena@gmail.com. 


\section{INTRODUÇÃO}

No trabalho com o ensino de literatura, percebemos, muitas vezes, devido ao constante contato com o texto escrito e a necessidade de aprendizado de sua leitura como exigência social, uma tendência a dar-se ênfase maior ao conhecimento por meio da leitura do texto, o que é necessário e indiscutível. No entanto, essa ênfase pode levar a práticas que desvinculam as experiências de mundo e do texto, como, por exemplo, o trabalho direcionado apenas à decifração e à percepção estrutural. Faremos, aqui, a partir de referências que se direcionam à figura do leitor, considerações sobre aspectos extrínsecos ao texto que influenciam o ensino da literatura e a percepção do ético e do estético na leitura do texto literário, visando a um equilíbrio entre ambas as experiências.

Paulo Freire, nas primeiras páginas do livro $A$ importancia do ato de ler, conta sua própria história como leitor. Seu intuito é ilustrar e desenvolver a ideia de "leitura" de mundo, palavra inicialmente colocada entre aspas, evidenciando sua intenção metafórica. Freire descreve, com detalhes, os elementos que constituíram a evolução de sua percepção de mundo: cantos de pássaros, o balanço da copa das árvores pelas ventanias, nuvens, plantas e árvores com seus frutos e suas cores, animais, o universo da linguagem dos mais velhos etc. Após a série de recordações, diz: "No esforço de retomar a infância distante, a que já me referi, buscando a compreensão do meu ato de ler o mundo particular em que me movia [...] re-crio, re-vivo, no texto que escrevo, $a$ experiência vivida no momento em que ainda não lia a palavra" (FREIRE, 1989, p. 12, grifo nosso). Ele continua sua rememoração, não apenas descrevendo as coisas de sua realidade, mas, também, dizendo como estabelecia relação entre elas: entre ventanias e chuvas, entre a escuridão e as almas penadas nas histórias dos velhos, entre o clarear e o canto dos pássaros. Fala, também, de como ia perdendo seus temores, conforme ia se tornando "íntimo" do seu mundo, percebendo-o e entendendo-o melhor.

Uma palavra-chave do relato de Freire, a partir da qual queremos propor algumas reflexões a respeito do ensino da leitura do texto literário, é "experiência". A intenção aqui é apontar de que forma uma reflexão a respeito da experiência, e da possibilidade de sua transmissão, pode contribuir para se repensar aspectos do ensino que são anteriores ao trabalho direto com a palavra escrita, ou, ao menos, concomitantes a ele. Dizendo de outro modo, e concordando com a ideia de que "a leitura de mundo vem antes da leitura da palavra", pretendemos aplicá-la ao ensino da literatura, não apenas repetindo proposições do método freireano, mas aproveitando-nos de sua imagem como educador, para sugerir que o ensino de literatura possa ser entendido como uma situação de transmissão da experiência, conforme a entende Walter Benjamin (1994), na qual a personalidade do professor, como sujeito empírico, é elemento essencial, assim como sua função no contexto restrito da comunidade escolar. Essa é uma afirmação aparentemente óbvia, no entanto, ela precisa ser vista na perspectiva do olhar para os sujeitos, em sua relação uns com os outros e com o mundo, antes de se olhar para sua relação com o texto escrito.

Quanto ao processo de leitura do texto escrito, pretende-se, aqui, evidenciar elementos presentes em referências importantes para o ensino da literatura, como Rildo 
Cosson (2014), Maria Helena Martins (1988), Annie Rouxel (2013) e Teresa Colomer (2011), mas a partir das reflexões de Bakhtin (2006) sobre a atividade estética, baseadas, inicialmente, numa reflexão elementar sobre as relações entre eu/outro, exercício do olhar que antecede a leitura da palavra escrita. É desse ponto que partiremos para, em seguida, percebermos os desdobramentos das atividades ética e estética, conforme as define Bakhtin, no contexto do ensino da literatura e nos efeitos para $O$ desenvolvimento da leitura, entendida como habilidade de percepção do texto escrito.

\section{2 “LEITURA” DE MUNDO: O ÉTICO E O ESTÉTICO}

No texto $O$ autor e a personagem na atividade estética, Bakhtin parte da verificação de um dado elementar da experiência para propor sua compreensão sobre a relação entre autor e personagem, a partir da qual vai definindo o que são atos éticos e estéticos: a relação eu/outro. Antes, no entanto, de tratar especificamente da apreciação de um objeto artístico, parte da seguinte constatação referente ao mundo concreto: "quando contemplo no todo um homem situado fora e diante de mim, nossos horizontes concretos efetivamente vivenciáveis não coincidem." (BAKHTIN, 2006, p. 21). Nada mais óbvio e, no entanto, é sobre essa simples assertiva acerca de uma experiência do mundo sensível que o autor constrói sua argumentação sobre a atividade estética.

A exotopia, a distância factual entre mim e os outros, o lugar único que ocupo no mundo, possibilita, para mim, um excedente de visão que me permite ver, em relação ao outro, algo que ele não vê (partes de seu corpo, o mundo atrás de si etc.) e, portanto, posso, como sujeito, dar-lhe acabamento (de imagem, de sua relação com o fundo físico e contextual, de sua forma de reagir sentimentalmente a um estímulo), completando-o “justamente naqueles elementos em que ele não pode completar-se.” (BAKHTIN, 2006, p. 23). Essa é a posição do autor para Bakhtin, correspondendo à personagem a posição daquele que vive numa relação eu-mundo direta e recebe o acabamento do autor. $\mathrm{O}$ outro/personagem é aquele que vejo, a partir do meu lugar único da existência, que vivencia a vida sem estabelecer distanciamento em relação a si mesmo.

Bakhtin discorre extensamente sobre as variáveis possíveis dessa primeira colocação: vivenciamento do outro por mim, do eu por mim mesmo, de mim pelo outro. Em todas, mantém, de forma mais ou menos complexa, a perspectiva inicial de que "eu sou o sujeito de qualquer espécie de ativismo: do ativismo da visão, da audição, do tato [...] etc. [...] o objeto se contrapõe a mim-sujeito [...] o outro indivíduo está todo no objeto para mim, e o seu eu é apenas objeto para mim.” (BAKHTIN, 2006, p. 36). Apesar da aparente unilateralidade da proposição, uma vez que ela estabelece uma relação direta entre sujeito e objeto e não entre sujeitos, é preciso lembrar que o ponto de partida é a visão e, sendo assim, sem exceções (afirmativa de Bakhtin), dois indivíduos não podem ocupar o mesmo lugar e, portanto, possuir ponto de vista idêntico sobre as coisas. Nesse jogo, apenas duas opções são possíveis: ou ver, ou ser visto. A noção de sujeitos que interagem, constituídas teoricamente a partir dessa relação visual, pertencem ao âmbito do conhecimento teórico e não constituem a experiência dos atos singulares únicos e irrepetíveis da existência, que é o que define o ético para 
Bakhtin ${ }^{1}$. Não a constituem porque, no ato ético, o conjunto das coisas do mundo que o sujeito vê, incluindo-se outros sujeitos, são objetos para ele.

Qual a importância desse princípio proposto por Bakhtin para a leitura do texto literário e para o ensino da literatura? Ele parece se insinuar em algumas ideias recorrentes que se debruçam sobre a relação entre leitor e texto.

Maria Helena Martins, em seu texto $O$ que é leitura, chama a atenção, inicialmente, para o fato de que, por vezes, objetos que vemos rotineiramente, num determinado momento, podem nos chamar a atenção e ganhar um sentido que antes não possuíam. Esse ato diferente e único passa a ser uma outra fase de nossa percepção, uma "leitura", afinal, segundo ela, que sugere, então uma semelhança com a leitura do escrito: "será assim também que acontece com a leitura de um texto escrito?” (MARTINS, 1988, p. 9). Mais adiante, reforça a semelhança dos atos perceptivos, entre a vida e o texto:

[...] quando começamos a organizar os conhecimentos adquiridos a partir das situações que a realidade impõe e da nossa atuação nela; quando começamos a estabelecer relações entre as experiências e a tentar resolver os problemas que se nos apresentam - aí então estamos procedendo leituras, as quais nos habilitam basicamente a ler tudo e qualquer coisa. (MARTINS, 1988, p. 17).

Veja-se aí, mais uma vez, a palavra "leitura", assim como em Freire, se aplicando metaforicamente à percepção de "qualquer coisa". Considerando os termos de Bakhtin, o mundo e tudo o que nele existe, incluindo-se outros sujeitos e os textos escritos, é passível, como objeto, ao ato ético e à contemplação estética. Martins tem a mesma clareza de que é preciso ver a leitura como um gesto direcionado ao mundo, libertador e que deve ser usufruído por todos e não apenas os letrados. É preciso sempre reafirmar essa proposição, pois, a todo momento, corremos o risco de sobrevalorizar a leitura da escrita em detrimento das outras "leituras", como se apenas ler o texto escrito fosse suficiente (ou o único meio) para que o indivíduo desenvolva senso crítico e estético e capacidade de abstração.

Maria Helena Martins propõe três níveis de leitura: o sensorial, o emotivo e o racional; sendo eles inter-relacionais e simultâneos, ou seja, não há entre eles necessariamente uma gradação. O nível sensorial toca aspectos elementares, como textura, cheiro, cores etc. Mas é nos níveis emocional e racional que o princípio bakhtiniano da exotopia pode ser pensado, na medida em que o emocional é o nível em que há identificação do indivíduo com os elementos vivenciados (não apenas no texto) e a racional é o nível em que o leitor retorna a si, após a leitura do texto, para estabelecer

\footnotetext{
${ }^{1}$ Uma reflexão mais detalhada sobre o desenvolvimento das ideias de autor e personagem, cujo intuito foi tratar da noção de narrador na obra de Bakhtin, pode ser vista no texto O narrador em Mikhail Bakbtin, de Everton Barbosa (2012). Recuperamos um trecho sobre o ato ético, a partir da leitura de Para uma filosofia do ato: "todo ato concreto ocorre apenas uma vez. A partir do momento em que um participante comece a pensar sobre a vida, ela já realiza um exercício de estar "fora" dela [...] teoria e estética não são a própria vida, mas como atos de pensamento e linguagem elas se tornam constituintes da vida, do acontecimento único e singular da existência." (BARBOSA, 2012, p. 38). A ideia de dois sujeitos que interagem seria, dessa forma, construção teórica para tratar de uma relação que se dá, num acontecimento singular e único da existência, entre um sujeito que vê e outro que é visto.
} 
um diálogo com sua própria experiência, seu conhecimento adquirido e seu contexto. A leitura emocional "revela a predisposição do leitor de entregar-se ao universo apresentado no texto, desligando-se das circunstâncias concretas e imediatas" (MARTINS, 1988, p. 58). Na leitura racional, "ao mesmo tempo que o leitor sai de si, em busca da realidade do texto lido, sua percepção implica uma volta à sua experiência pessoal e uma visão própria do texto (MARTINS, 1988, p. 66). De modo semelhante, Annie Rouxel (2012), alinhada com os pressupostos da estética da recepção, defende a importância do que denomina leitura cursiva, para que se considere a experiência do leitor, na medida em que introduz na leitura escolar um espaço de liberdade para o sujeito, não previsto na leitura analítica, aquela que submete o leitor às injunções do texto: "é preciso encorajar as abordagens sensíveis das obras, atentar para a recepção dos alunos ou daquilo que eles aceitarão manifestar de sua experiência estética." (ROUXEL, 2012, p. 10)

Note-se aí um movimento de "saída e retorno" do eu em relação a si mesmo e aos "textos" que lê, embora Martins dê mais ênfase à leitura do texto escrito na leitura racional e Rouxel se refira a práticas de leitura na escola. Bakhtin define as atividades ética e estética de forma semelhante:

Quando me compenetro dos sofrimentos do outro, eu os vivencio precisamente como sofrimentos dele, na categoria do outro, e minha reação a ele não é um grito de dor e sim uma palavra de consolo e um ato de ajuda. Relacionar ao outro o vivenciado é condição obrigatória de uma compenetração eficaz e do conhecimento tanto ético quanto estético. A atividade estética começa propriamente quando retornamos a nós mesmos e ao nosso lugar fora da pessoa que sofre, quando enformamos e damos acabamento ao material da compenetração. (BAKHTIN, 2006, p. 25).

Essa ideia do retorno a si após o vivenciamento do outro parece se referir aos mesmos processos de leitura emocional e racional de Martins. A leitura emocional corresponderia ao vivenciamento do outro/personagem, e a racional seria produto do retorno a si, próprio da atividade estética, conforme definida por Bakhtin, em que o eu/autor pode dar acabamento ao outro/personagem. Outras expressões transmitem ideias semelhantes. Vincent Jouve, por exemplo, usa a expressão "recuo crítico", para se referir ao processo de distanciamento em relação à história, a partir do que o leitor "sai mais consciente de sua leitura (JOUVE, 2002, p. 134). Faz essa colocação no âmbito de uma reflexão sobre o impacto da leitura no leitor, considerando previamente que as leituras podem tanto confirmar as crenças e expectativas do leitor, quanto desestabilizálas, transformando-o e fazendo-o se redescobrir. Essa redescoberta é a intenção do estético para Bakhtin que, de forma radical, diz que se não houvesse esse retorno a si, "ocorreria o fenômeno patológico do vivenciamento do sofrimento alheio como meu próprio sentimento [...] e só. A rigor, a compenetração pura, vinculada à perda do nosso único lugar fora do outro, e quase impossível, e [...] totalmente inútil e sem sentido.” (BAKHTIN, 2006, p. 24).

A assertiva radical de Bakhtin se dá pelo fato de que ele entende o evento estético como algo necessário ao ser humano, no sentido de sua transformação pessoal e responsável. Apesar disso, reafirma em vários momentos que o vivenciamento do outro 
é parte constituinte da atividade estética, mas não consiste em sua etapa final, que só se dá no retorno do eu/autor à sua posição externa e excedente ao outro/personagem. Essa reflexão pode nos ser útil para entender o direcionamento para o leitor, do trabalho com ensino da leitura da literatura. É possível ver um apelo de autores importantes, antigos e novos, no sentido de valorizar as experiências pessoais do leitor e de deixá-lo em contato direto com obras. As leituras sensorial e emocional vistas anteriormente, sugeridas por Martins, evocam esse sentido da experiência primária da abordagem de um texto, embora ela defenda a simultaneidade dos níveis e não uma progressão sequencial, como sugere Bakhtin.

Jouve, por sua vez, reconhece o processo de identificação com as personagens na narrativa como ato importante no processo de leitura, sugerindo que, por meio dela, pareça "de fato a verdade de sua própria vida que o leitor está em condição de apreender: a leitura, ao fazê-lo atingir uma percepção mais clara de sua condição, permite-lhe entender-se melhor." (JOUVE, 2002, p. 134). Antonio Candido chama a atenção às impressões no subconsciente que uma leitura pode promover, cujos resultados são imprevisíveis, incontroláveis e, mesmo, imperceptíveis: "quero dizer que as camadas profundas da nossa personalidade podem sofrer um bombardeio poderoso das obras que lemos e que atuam de maneira que não podemos avaliar." (CANDIDO, 1999, p. 83).

Mais recentemente, Langlade e Rouxel (2013) propuseram o termo "leitura subjetiva", chamando a atenção para a necessidade de se olhar para a experiência de vida/leitura do leitor no contexto do ensino, reconhecer suas necessidades, gostos. Sugerem que há "ressonâncias" entre texto e leitor que mantém vivo o texto: o texto vive de suas ressonâncias com as lembranças, as imagens mentais, as representações íntimas de si, dos outros, do mundo do leitor. (LANGLADE, 2013, p. 31). Ressonâncias são ecos, sons que se repetem ou se refletem de alguma forma em elementos distintos (nesse caso, texto e leitor). Poderíamos dizer que ressonância funciona, nesse contexto, como sinônimo de empatia ou identificação, que ocorre entre leitor e obra. A questão aqui não é analisar Langlade a partir de Bakhtin, mas apenas mostrar ressonâncias/identidades entre suas ideias. Uma diferença evidente é que o termo "ressonância" sinaliza um sentido sonoro, enquanto identificação sugere um sentido visual e há uma grande diferença entre essas duas modalidades, no que se refere às relações entre autor/texto/leitor. Essa diferença, no entanto, não será tratada aqui, pois a ideia de ressonância estaria mais próxima à ideia de polifonia ou bilinguismo, o que demandaria outro desenvolvimento para esse texto.

No mesmo capítulo, Langlade trata de uma distância crítica, o que poderia nos remeter às noções de exotopia ou recuo crítico, no entanto, essa distância não estaria necessariamente associada à contemplação estética, mas sim, a "reações afetivas", em que o leitor estabelece "uma distância crítica com ela [obra], mesmo que essa distância crítica não se queira uma análise formal do texto.” (LANGLADE, 2013, p. 36). Considerando o que diz Bakhtin, apesar de a atividade estética não estar restrita à análise formal, ela também não se constituiria como ato de reação afetiva, que se vincularia mais propriamente ao ato ético em relação ao outro/personagem. Assim como 
Langlade, no mesmo livro, Annie Rouxel também procura desenvolver a proposta da leitura subjetiva, partindo da diferença entre "usar" e "interpretar" o texto, baseando-se nos conceitos homônimos de Umberto Eco, a partir do que, ela conclui:

[é] indispensável hoje fomentar entre os alunos uma abordagem sensível dos textos, mesmo que seja da ordem da utilização [...] o desafio é fazer viver uma experiência de leitura, sem a qual a atividade, puramente cerebral, não faria sentido algum aos alunos. (ROUXEL, 2013, p. 162, grifo nosso).

Usar o texto tem a ver com se apropriar particularmente dele, independentemente do fato de já haver algum consenso sobre sua interpretação, que se constitui como leitura consolidada e coletiva. Não importa, nesse caso, se já há leituras prévias que indicam caminhos para o texto, mas apenas uma relação pessoal e intransferível entre ele e seu leitor.

Chamando a atenção para a necessidade de um contato direto e primeiro com a obra, é importantíssima a colocação de Rouxel, na medida em que, da mesma forma que Langlade, lança uma crítica contundente a uma forma específica de se lidar com o ensino de literatura, que incide em práticas tradicionais como: estudos formais (como menciona Langlade), leituras comentadas a partir da interpretação do professor, uso do texto literário como pretexto para outros conteúdos, leitura do texto como expressão de seu autor ou contexto social etc. Todas elas são atividades que atribuem sentido ao texto previamente à própria leitura pelo aluno. Essas são práticas criticadas desde o século passado, mas parecem caracterizar ainda de forma frequente o ensino da literatura, uma vez que é uma observação constante em boa parte dos textos que propõem novas abordagens. Frente a elas, veem-se coincidir as propostas no sentido de ofertar a experiência direta com a leitura literária, que se efetiva no "encontro pessoal e intransferível entre o leitor e a obra" (COSSON, 2018, pos. 2347), ou conforme a percepção de que toda obra "engendra uma multiplicidade de obras originais produzidas pelas experiências, sempre únicas, dos leitores empíricos...” (LANGLADE, 2013, p. 32).

Podemos, talvez, concluir momentaneamente, que os autores mencionados coincidem em realizar uma exigência ética no tratamento da leitura da literatura. O contato entre leitor e obra deveria se dar sem intermediação antecipada do universo cognitivo, que é aquele em que o conhecimento sobre leituras já se acumulou. A experiência ética do sujeito leitor com o texto deveria ser estimulada, ainda que não seja ela o ato que caracteriza propriamente a experiência estética, se concordarmos com Bakhtin. Em outras palavras, exige-se que o ato de leitura se dê como acontecimento singular e único da existência e, para tal, o procedimento mais adequado seria o da leitura inicial sem intermediações (do professor, da tradição interpretativa etc..).

Duas observações são importantes em relação a essas reflexões: o contato do leitor com o texto pode ser entendido pelos mesmos parâmetros que o contato entre eu/autor e outro/personagem: o leitor, frente ao personagem, ocupa também o lugar de autor; na necessidade de haver uma "leitura" de mundo anterior à leitura da palavra, seria preciso desenvolver aquela primeiramente, especialmente nos casos em que houver carência de experiência/leitura de mundo, como sugere Freire: 
Em áreas cuja cultura tem memória preponderantemente oral e não há nenhum projeto de transformação infra-estrutural em andamento, o problema que se coloca não é o da leitura da palavra mas o de uma leitura mais rigorosa do mundo, que sempre precede a leitura da palavra. (FREIRE, 1989, p. 43).

Reiteramos, então, a necessidade de se pensar a "leitura" que ocorre antes da palavra, para que haja mais clareza nas exigências que se faz em relação à necessidade da experiência com a literatura e os benefícios que ela traz, para não incorrermos no risco de sobrevalorização da leitura do texto literário em detrimento da leitura de mundo, o que pode, muitas vezes, conduzir novamente a uma valorização do alfabetizado sobre o analfabeto, como sugere Maria Helena Martins. Acreditamos que, atualmente, as condições são ainda mais complexas que as de uma cultura cuja memória é "preponderamente oral". Hoje, constata-se, nos grandes centros, a ausência de cultura nos moldes da tradição oral. Há uma flagrante falta de experiência, no sentido que será considerado adiante, e tratar disso é, mais uma vez, chamar a atenção para o mundo que existe antes da palavra escrita.

\section{3 “LEITURA” DE MUNDO: A EXPERIÊNCIA}

$\mathrm{Na}$ possibilidade de transmissão da experiência com a leitura (e não com o conteúdo das leituras feitas), poderemos pontuar alguns aspectos que julgamos importantes na formação do professor e de seu lugar de autoridade no contexto educacional. Partimos da ideia de que, especialmente aquele sobre o qual recai a responsabilidade do trabalho com a leitura precisa ser, antes, um leitor experiente e, em sua constituição como tal, precisa, necessariamente, experimentar a "leitura" de mundo e ter consciência das relações entre essa "leitura" e a leitura da palavra.

Todorov, no livro $A$ literatura em perigo, também recupera sua história como acadêmico e leitor de literatura e enfatiza, de início, como sua experiência com a literatura substituía sua experiência com a realidade:

[...] eu podia satisfazer minha curiosidade, viver aventuras, experimentar temores e alegrias, sem me submeter às frustrações que espreitavam minhas relações com os garotos e garotas da minha idade e do meu meio social. (TODOROV, 2009, p. 16).

No livro, Todorov faz um exame do estruturalismo como corrente que influenciou a educação na França e em outros países ${ }^{2}$, após maio de 1968. Lembra-se de que estudou os aspectos formais da língua e da literatura em seu país para escapar às perseguições políticas de um regime autoritário, uma vez que a forma seria um objeto neutro e o estudo temático só poderia contemplar temas ligados à ideologia do governo.

\footnotetext{
${ }^{2}$ Hoje, podemos pensar que o erro do ensino literário na escola se deveu ao tipo e nível dos instrumentos de interpretação literária que foram postulados. Não era pertinente que as crianças do primário aplicassem as "funções" que o formalista russo Vladimir Propp estabeleceu como constitutivas dos contos populares maravilhosos à leitura e escrita de seus próprios contos, como se fez; (COLOMER, 2011, pos. 550, tradução nossa).
} 
Progredindo em sua carreira, e já influente na França, Todorov percorreu algumas escolas como membro de comissão avaliadora do ensino e percebeu a forte presença de conteúdos do estruturalismo nos trabalhos ligados à língua e à literatura. Reflete, então, sobre essa presença como um engano, fruto da apropriação e aplicação, por parte do sistema educacional, de estudos que não deveriam compor o ensino básico, argumentando que "no ensino superior é legítimo ensinar as abordagens, os conceitos postos em prática e as técnicas. O ensino médio não pode ter o mesmo alvo; o que se destina a todos é a literatura, não os estudos literários.” (TODOROV, 2009, p. 41).

Todorov permite, com isso, duas reflexões importantes: uma sobre como a influência política de um movimento pode gerar enganos a médio e longo prazo; outra sobre o que seria efetivamente importante no trabalho com a literatura. Suas colocações se afinam com o que já foi colocado aqui anteriormente sobre a necessidade do trabalho com a literatura que enfatize a ética, entendida como experiência direta e única com o texto e, antes dele, com a vida. Nesse sentido, mais uma vez, enfatizamos a necessidade de perceber que a experiência com fatos concretos da existência é fundamental para a formação do leitor e, como o próprio Todorov conclui em seu livro, a experiência com a leitura da palavra não substitui a experiência de mundo:

A literatura me ajuda a viver: não é mais o caso de pedir a ela... que me preservasse das feridas que eu poderia sofrer nos encontros com pessoas reais; em lugar de excluir as experiências vividas, ela me faz descobrir mundos que se colocam em continuidade com essas experiências e me permite melhor compreendê-las. (TODOROV, 2009, p. 23).

Essa percepção de continuidade e complementaridade entre vida e texto é fundamental para a formação do professor que trabalha com a literatura em sala. $\mathrm{Na}$ lida em sala de aula com a leitura, os riscos de uma alienação em relação à experiência concreta são muitos, não só pela ausência do trabalho com temas familiares aos alunos (problema ainda persistente), mas, também, porque o vínculo da literatura com a realidade e a necessidade de se trabalhar a experiência de vida antes da literária pode não estar muito claro para o próprio professor. Certas noções de leitura, nesse contexto, acabam por se reproduzir. Jouve aponta algumas delas, a partir de referências de Jauss e Sartre. Diz, por exemplo, que "a leitura é portanto, ao mesmo tempo, uma experiência de libertação ("desengaja-se" da realidade) e de preenchimento (suscita-se imaginariamente... um universo marcado por seu próprio imaginário).” (JOUVE, 2002, p. 107). Obviamente, há a contrapartida, apontada por Jouve, de uma reformulação da visão de mundo do leitor, a partir de sua experiência com a leitura, mas acreditamos que essa transformação é a que mais depende da percepção de que a experiência de vida é importante e anterior à leitura do texto. No universo restrito da experiência escolar, o envolvimento mais intenso com a leitura pode levar à concepção evidenciada por Todorov:

Não tomemos como dogma inabalável os axiomas românticos, de que a "verdadeira vida é a literatura", ou que "tudo no mundo existe para se conduzir a um livro", dogma que excluiria três quartos da humanidade da "verdadeira vida". (TODOROV, 2009, p. 92). 
Isso porque, da mesma forma que o estruturalismo influenciou, de maneira equivocada, a educação francesa pós-68, instituindo o estudo formal na educação básica, ideias como a de que "tudo é texto" (inclusive a natureza, comparada a um "livro"), ou, ainda, a de que "o real só existe na linguagem e por meio dela", podem, mesmo que esta não tenha sido a intenção original das correntes que as engendraram, causar uma confusão nas noções "leitura" de mundo e leitura da palavra, quando mal compreendidas, e prejudicar o trabalho pedagógico do professor em vez de contribuir com ele.

Por isso, afirmar a necessidade da "leitura" de mundo antes da leitura da palavra, apesar de parecer uma observação óbvia e desgastada, é ainda necessária. Em texto recente, Jorge Larrosa parte da ideia de experiência para tratar do trabalho com a leitura da literatura. Assim como Bakhtin, parte de um pensamento elementar, de que experiência é "tudo o que nos acontece". Seu objetivo é "pensar a educação a partir do par experiência/sentido" (LARROSA, 2014, pos. 141). Apoiando-se nas reflexões de Walter Benjamin, em seu ensaio $O$ narrador, tece suas argumentações a respeito das ideias de "informação" e "empobrecimento da experiência", para falar de como certos aspectos da realidade contemporânea, em especial no contexto escolar, acabam por influenciar o processo educacional. Sobre a informação, o autor é categórico:

O sujeito da informação sabe muitas coisas, passa seu tempo buscando informação, o que mais o preocupa é não ter bastante informação; cada vez sabe mais, cada vez está mais bem informado, porém, com essa obsessão pela informação e pelo saber (mas saber não no sentido de "sabedoria", mas no sentido de "estar informado"), o que consegue é que nada lhe aconteça. (LARROSA, 2014, pos. 159).

Apesar da impressão inicial de que estar bem informado dá status positivo ao indivíduo contemporâneo, e isso implica acompanhar cotidianamente as atualizações constantes das informações, essa prática não se constitui necessariamente como experiência, no âmbito do ético. Entendemos que o sujeito que vive submetido ao fluxo de informações, cada vez maior, da atualidade, é um sujeito que está, em boa parte do seu tempo, solitário em frente ao suporte pelo qual as obtém. Sua experiência é, nesse sentido, mais cognitiva do que ética. O indivíduo ávido por informações olha para o texto mais do que para o mundo, portanto, não o experimenta diretamente. Por isso, arrisca-se a que nada lhe aconteça. Consideramos, para tal compreensão, a perspectiva do ato ético, segundo Bakhtin: o acontecimento singular e irrepetível da existência. A leitura consiste em ato individual e solitário ${ }^{3}$, ainda que se possa argumentar que haja diálogo com um autor/leitor implícito. Estes, no entanto, não são sujeitos empíricos, não fazendo, pois, parte da experiência ética, mas sim, da cognitiva.

Essa solidão que vive o sujeito consumidor da informação, bem como a própria dinâmica do funcionamento da informação, são indícios do empobrecimento da experiência, se considerarmos as ideias de Walter Benjamin. O sujeito vive ávido pela informação sem se dedicar à construção de um saber cujos efeitos em si são mais

3 Teresa Colomer, inclusive, sugere a "solidão" como uma das condições necessárias para o desenvolvimento da prática de leitura. (COLOMER, 2011, pos. 2041). 
duradouros e marcantes: procura-se estar "bem informado" e não a sabedoria. Diz Walter Benjamin: "cada manhã recebemos notícias de todo o mundo. E, no entanto, somos pobres em histórias surpreendentes. A razão é que os fatos já nos chegam acompanhados de explicações." (BENJAMIN, 1994, p. 203). A partir dessa afirmação, destacamos dois aspectos importantes sobre a informação. Há, por um lado, a banalização do efeito de novidade das informações, e, por outro, o esvaziamento da autoridade (ou mesmo da imagem) do sujeito concreto que informa, pois vale mais o conteúdo de sua informação do que sua própria experiência. A informação se apresenta aparentemente desvinculada de um sujeito real emissor e se quer recebida como verdade imparcial. Em resposta, Larrosa retorna ao âmbito do ético, afirmando que o saber da experiência "é um saber que não pode separar-se do indivíduo concreto em quem encarna... somente tem sentido no modo como configura... uma forma humana singular de estar no mundo." (LARROSA, 2014, pos. 344).

Larrosa destaca mais aspectos que podem ser entendidos como empobrecedores da experiência, vinculados ao consumo da informação:

\begin{abstract}
A velocidade com que nos são dados os acontecimentos e a obsessão pela novidade, pelo novo, que caracteriza o mundo moderno, impedem a conexão significativa entre acontecimentos. Impedem também a memória, já que cada acontecimento é imediatamente substituído por outro que igualmente nos excita por um momento, mas sem deixar qualquer vestígio. $\mathrm{O}$ sujeito moderno não só está informado e opina, mas também é um consumidor voraz e insaciável de notícias, de novidades, um curioso impenitente, eternamente insatisfeito. Quer estar permanentemente excitado e já se tornou incapaz de silêncio (LARROSA, pos. 202. grifos nossos).
\end{abstract}

Percebemos que os aspectos destacados, caracterizam o empobrecimento da experiência do sujeito na sociedade, mais ainda, interferem no processo educacional, especialmente no ensino de literatura. Para a leitura do texto literário e, consequentemente, o trabalho com a literatura na escola, é importante considerar a influência que têm, no indivíduo, os fatores elencados até aqui: o isolamento social do sujeito, a vivência de mundo por meio da informação mais do que pela experiência, a ansiedade pela novidade, a dificuldade de estabelecer conexão entre acontecimentos, a dificuldade de memorização e a incapacidade de estar em silêncio e se concentrar. Consideramos que, antes da leitura do texto, é preciso intervir sobre esses fatores. Além desses, outros também precisam ser considerados: a dinâmica da moda, da obsolescência programada (que obriga o consumidor a atualizar constantemente seus produtos), da predominância da linguagem imagética em detrimento da escrita (o que desfavorece a prática da imaginação), do consumo de arte como entretenimento etc.

Esses fatores podem ser vistos, inclusive, na própria produção literária. Teresa Colomer fala, por exemplo, da tendência "a fragmentar o discurso narrativo, provocada talvez pela ideia de que as crianças estão habituadas a relatos audiovisuais e têm pouca capacidade para se concentrar em unidades longas." (COLOMER, 2011, pos. 1448). Acompanhar essa tendência não é algo errado ou condenável, mas, se acreditarmos nas considerações de Benjamin e Larrosa, essas produções apenas reforçam a dinâmica

${ }^{4}$ Tradução nossa. 
social, visando acompanhar o desenvolvimento das práticas sociais e de leitura baseadas em elementos que desfavorecem a experiência.

Considerar esses fatores, no trabalho com a literatura, pode constituir-se como preparação para a leitura do texto, assim como o estímulo à vivência do real, ao qual a literatura responderá posteriormente. É claro que ela pode fornecer modelos de interpretação para a realidade, transformando o sujeito a partir da leitura, fazendo com que veja de outra forma os acontecimentos posteriores. Esse resultado é mais efetivo quando o sujeito já se constitui como leitor, mesmo iniciante. Enfrentamos, no entanto, o fato de que, muitas vezes, não há, no sujeito pobre de experiências, a própria disposição para a leitura. Trabalhar a experiência com o mundo tem o intuito de fazer perceber justamente os fatores que limitam aquela disposição. Um exemplo dado por Colomer é a dificuldade de se lidar com o fracasso:

Em geral, as crianças não estão acostumadas a fracassar quando chegam à escola. Aprender a ler e escrever é, para muitos deles, a primeira experiência de que podem não alcançar as expectativas do que se espera deles. E, rapidamente, geram defesas para proteger sua autoestima. ${ }^{5}$ (COLOMER, 2011, pos. 1911).

Trabalhar com esse sentimento, antes de se trabalhar com a leitura, pode ser uma estratégia pertinente para preparar o aluno para a experiência com o literário. Essa sugestão pode ser questionada, no que se refere às restrições das áreas do conhecimento: o trabalho com o sentimento de frustração não seria competência do professor de linguagens, no contexto escolar. No entanto, ela abre possibilidade justamente para a realização de uma ideia muito cara hoje para o ensino, mais defendida do que praticada: a interdisciplinaridade. Sabemos que isso envolve uma reflexão sobre a organização do trabalho docente e sobre a forma de registro, controle e divisão das competências do profissional do ensino, que incidem mais no indivíduo do que no grupo. No entanto, é uma reflexão urgente e necessária, uma vez que permite atuar mais precisamente nos fatores que atrapalham a aprendizagem e que não estão diretamente ligados ao conteúdo programático das disciplinas, como os já mencionados anteriormente.

É possível, apesar dessa sinalização para fora do âmbito do trabalho estrito com a literatura, ver, nas ideias de Walter Benjamin sobre o narrador, algumas possibilidades metodológicas, que respondem às condições sociais colocadas por Larrosa anteriormente. Primeiramente, é importante destacar que, no ensaio $O$ narrador, Walter Benjamin não está tratando de um componente da narrativa, mas do sujeito empírico que narra, apresentando a mesma tendência ao ético, explorada aqui em outros autores. Tratando-o como um tipo humano que já não existe mais, Benjamin dá uma definição muito sucinta e direta do narrador, como "um homem que sabe dar conselhos" e, a respeito do conselho, diz: "O conselho tecido na substância viva da existência tem um nome: sabedoria. A arte de narrar está definhando porque a sabedoria - o lado épico da verdade - está em extinção." (BENJAMIN, 1994, p. 200). Narrar, nesse sentido, é a "faculdade de intercambiar experiências." (BENJAMIN, 1994, p. 198).

\footnotetext{
5 Tradução nossa.
} 
Como vimos com Larrosa e Benjamin, o que impossibilita a capacidade de intercambiar experiências é o fato de que há empobrecimento ou mesmo inexistência da experiência. Diante disso, o que propomos é aproveitar alguns princípios relativos ao narrador e à narrativa, como operadores críticos para tratar do ensino de literatura. Assim como em Benjamin, esse exercício não se propõe como uma tentativa de "resgatar" o sujeito narrador perdido, mas, sim, de buscar possibilidades de enxergar sua permanência onde ele parece não existir mais: um mundo sem experiências. Reiteramos com isso, também, a ideia de que pensar o sujeito nesses moldes é pensar um dado do mundo, antes de se falar da leitura da literatura, o que percebemos que Benjamin também faz em seu ensaio: mais do que falar da narrativa, ele fala do sujeito concreto que narra. Para efeito deste artigo, a figura do narrador será tomada para tratarmos da figura do professor.

É recorrente a opinião, apoiada em Paulo Freire, de que o professor não transmite conhecimento, mas auxilia o aluno a aprender e aprende com ele. Da disputa entre essa correta opinião e a figura da tradicional autoridade do professor, que ainda persiste, parece não resultar um sentimento de autonomia, por parte do professor. Essa carência se reforça ainda mais pelo fato de que o conteúdo e os métodos a serem adotados na escola são dados, não a partir da própria experiência do professor, mas de forma institucional e arbitrária. O professor se vê, muitas vezes, desautorizado, tanto pelos alunos (sua comunidade imediata), quanto pelas diretrizes institucionais, a ter autonomia de decisão e condução em seu trabalho. Na perspectiva da possibilidade de troca de experiências no contexto de sala de aula, é necessário que o professor sinta que tem algo de si mesmo a transmitir, além do conteúdo. Quando não há esse sentimento, que estimula a troca de experiências (a sabedoria), o professor corre o risco de transmitir, mesmo de forma inconsciente, valores negativos, conforme a constituição de sua personalidade, incidindo no que diz José Pacheco: "um professor não ensina aquilo que diz; o professor transmite aquilo que é.” (PACHECO, 2012, p. 11). É preciso, então, que haja esse olhar para si mesmo e o desenvolvimento da autoconfiança em sua própria história de vida e conhecimento. Em Benjamin, essa autoconfiança vem do fato de que o narrador "pode recorrer ao acervo de toda uma vida (uma vida que não inclui apenas a própria experiência, mas em grande parte a experiência alheia...).” (1994, p.221). De que forma, no entanto, num contexto em que a sabedoria tem pouco espaço, pode-se minimamente exercer atos que indicariam traços dela? De que forma o professor, muitas vezes já formado sob a dinâmica da informação e da falta de experiência, num contexto de esvaziamento da figura do sujeito e a possibilidade de sua autoridade, pode exercer a troca de experiências no trabalho com a leitura?

Além da capacidade de intercambiar experiências, diz Benjamin que também está desaparecendo "o dom de ouvir, e desparece a comunidade dos ouvintes. Contar histórias sempre foi a arte de contá-las de novo, e ela se perde quando as histórias não são mais conservadas." (1994, p. 205). O contexto oral pressupõe, dessa forma, um senso de coletividade e interdependência entre sujeitos, no que se refere à troca de experiências pela linguagem. Diferentemente dos atos de escrita/leitura, na oralidade jamais os atos serão solitários. Em relação à memória, enquanto a informação é um 
dado que possui uma vida curta e exige renovação constante, a narrativa é algo que sobrevive pela repetição ao longo do tempo. Dessa forma, para que a narrativa se mantenha, será preciso sempre manter-se o vínculo entre os sujeitos. Minimamente, é o que propõe Teresa Colomer, quando sugere que

[...] foi neste campo que surgiu, com maior força, a percepção de uma necessidade crescente de escutar. Mais que descobrir por que não leem, se trata de escutar os jovens, que leem sim, apesar do contexto, para saber o quê os motiva a fazê-lo. ${ }^{6}$ (COLOMER, 2011, pos. 2120).

Ainda que sua sugestão parta da experiência de recuperação de leitores a partir de leitura de livros, o ato de "escutar" implica o encontro entre professor e aluno e a atenção às necessidades e às expectativas deste, sugestão muito semelhante às de Paulo Freire. Duas situações são possíveis aí: uma em que os alunos são leitores e apenas não leem livros recomendados pela escola; outra em que os alunos não são leitores e apenas dirigem sua atenção ao mundo informacional, predominantemente audiovisual. Em ambos os casos, a escuta se faz necessária, tanto para se ter conhecimento dos alunos e proximidade com eles, quanto para desenvolver o senso de comunidade entre eles. Não por acaso, Colomer diz que "cada vez puede afirmarse con mayor seguridad y en forma más pormenorizada que la lectura compartida es la base de la formación de lectores" (2011, pos. 1969). Cosson, de maneira semelhante, adota como "princípio do letramento literário a construção de uma comunidade de leitores.” (2014, pos. 646). Desenvolver e estimular o senso de pertencimento a uma coletividade é um fator que já demonstrou resultados concretos e esse é um princípio constituinte do narrador tradicional, pois é pela comunidade que ele é autorizado a narrar e seu relato ganha caráter de verdade.

Outro princípio importante a se considerar, no mesmo trecho citado de Benjamin, é uma experiência mais distendida do tempo, característica da narrativa. Considerando a afirmação de Larrosa, de que "a experiência é cada vez mais rara, por falta de tempo" (2014, pos. 225), entendemos que, não havendo tempo disponível, dificilmente dois requisitos necessários à sua recepção jamais poderão ser desenvolvidos de forma satisfatória: paciência e concentração. Num mundo em que não se tem tempo, no qual se trabalha demais e se dedica tempo ao acompanhamento diário de informações, não haverá espaço para atividades prolongadas, sejam orais ou escritas. A diferença entre a agitação diária e a pausa e o silêncio necessários para a troca de experiências não é produtiva no sentido do desenvolvimento da habilidade de leitura. Em relação ao tempo, Colomer dá sugestões importantes:

Os meninos e meninas também precisam de outras coisas: tempo na aula para praticar a leitura autônoma e rotinas cotidianas, para que se lhes "ocorra" que podem pegar um livro e não ligar-se ao rapping televisivo; alguém atento a equilibrar seu interesse impaciente pela história e sua leitura lenta. (COLOMER, 2011, pos. 2044).

6 Tradução nossa. 
Os alunos se recordam melhor da leitura de determinados textos se ela foi integrada na recordação global de uma atividade longa e com sentido próprio. ${ }^{7}$ (COLOMER, 2011, pos. 2249).

As duas sugestões da professora procuram responder aos desafios impostos pela falta de tempo: reservar tempo de aula para leitura e trabalhar atividades mais longas com objetivos específicos. Rildo Cosson, em sua proposta de sequência expandida, traz a mesma ideia de leitura prolongada, com a diferença de que "convém ser feita prioritariamente extraclasse." (COSSON, 2016, pos. 1206). Novamente, tanto Cosson quanto Colomer trazem suas experiências de trabalhos feitos diretamente com a leitura do texto. Frente à indisciplina, ansiedade, incapacidade de concentração para a leitura e outros fatores comuns ao cotidiano escolar, no entanto, caberão outros recursos não literários. Um exemplo de prática possível, ainda pouco exercitada por não corresponder a determinações curriculares, é a meditação, que promove experiências de vivência interior, de distensão do tempo e de silêncio, extremamente necessárias para o trabalho com leitura. Alguns relatos, de outras áreas, já indicam como essa atividade atua na mudança de comportamento do aluno, na sua relação com os professores e no rendimento escolar.

O estímulo ao senso de coletividade, ao dom de ouvir, à experiência do silêncio, à vivência de uma temporalidade mais distendida, à autoconfiança e autorização do professor em relação à sua própria história de vida, como sujeito histórico e responsável, que pode aconselhar e transmitir sua experiência como ser humano e como leitor, são fatores importantes que devem ser sempre considerados antes e concomitantemente ao trabalho com a leitura do texto literário. Essas observações se dão como complementares a todo o trabalho que vem sendo feito e divulgado a partir de atividades e reflexões centradas no leitor/aluno e que são igualmente importantes, mas que incidem sobre o trabalho com a leitura direta do texto e seus desdobramentos, mais do que tratar de aspectos da "leitura" de mundo, independente e anterior à leitura da palavra.

\section{CONSIDERAÇÕES FINAIS}

Resta associarmos as duas linhas gerais de reflexão deste artigo: uma que incide na relação eu/outro e seus desdobramentos; outra que enfatiza a figura do sujeito como pessoa concreta que pode trocar experiências. Consideramos que um traço importante que deve constituir o sujeito da experiência, nesse caso, o professor, é a consciência de

\footnotetext{
7 Tradução nossa.

8 Sugerimos as leituras de MORAIS; BALGA (2007), GROSSI; AGUINSKY (2006), MARTINS et al. (2018), LOPES; ROCHA (2018), ROCHA et al. (2015), pesquisadores das áreas de Educação Física e Pedagogia. Os textos estão disponíveis, respectivamente, nos seguintes links: http://editorarevistas.mackenzie.br/index.php/remef/article/view/1227/938, https://www.redalyc.org/pdf/848/84805909.pdf, https://7seminario.furg.br/images/arquivo/114.pdf, https://www.ulbracds.com.br/index.php/sieduca/article/view/1865/246, https://www.revistas.ufg.br/teri/article/view/38797.
} 
sua posição axiológica na relação eu/outro e a percepção de que essas são posições permutáveis. O professor vê os alunos, relaciona-se ética e esteticamente com eles, a partir de sua posição única na existência. Ao mesmo tempo, cada aluno vê o professor e os outros e também pode se relacionar ética e esteticamente com eles. Essa consciência, principalmente por parte do professor, pode funcionar como uma espécie de guarida contra a possível expectativa de que os alunos consigam ver as coisas como ele mesmo vê, ou que aprendam da forma como ele aprendeu. A educação, vista dessa forma, só pode consistir efetivamente numa troca, uma vez que, independentemente do que ocorra durante o processo, cada aluno e cada professor construirá seu conhecimento a partir de seu lugar único e singular da existência. A transferência pura e simples (de conhecimento, de conteúdo etc.) é, por esse princípio, impossível. Apesar disso, os processos de identificação na relação com o outro não deixam de existir, como ato ético, o que abre possibilidade também para a imitação e a reprodução de ideias, comportamentos e valores.

No trabalho com a leitura do texto literário, o professor, como sujeito experiente, pode perceber de que forma trabalhar a percepção de mundo dos alunos, a partir do que falam e fazem, de seu comportamento, das respostas que dão, inclusive, a leituras de textos e também a partir da forma como ele mesmo, professor, percebe o mundo de seu lugar único e singular na existência. É possível que um professor não tenha a mesma percepção a respeito do que se chamou aqui de empobrecimento da experiência e que julgue a dinâmica social uma consequência normal da evolução social, assim como a dificuldade de concentração e de disposição para exercícios longos de reflexão e de leitura. É possível que nem preste atenção a isso ou não tenha tempo para perceber, envolvido, muitas vezes, com atender demandas burocráticas que visam a controlar sua atividade laboral.

Nesse jogo intenso de pontos de vista, obrigações burocráticas, pressões sociais, excesso de trabalho e informação, em que disputam a reprodução de valores educacionais tradicionais e as tentativas de inovação e melhoria no rendimento dos alunos, torna-se extremamente difícil tomar decisões, principalmente as que se chocam com determinações institucionais que são alheias à realidade local em que o processo de ensino-aprendizagem acontece. Para enfrentar essas condições, o professor, ao trabalhar a leitura do texto literário, precisa, antes de tudo, ser um indivíduo com alguma experiência de vida, que lhe permita ter a paciência necessária para não se envolver plenamente nas tensões provocadas pelo cotidiano, distanciando-se criticamente delas para que possa construir sua compreensão das condições em que atua. Além disso, precisa ser experiente na atividade estética. Se ele se situa entre os que apenas lidam eticamente com a leitura, ou seja, apenas se envolvem emotivamente com ela, como sugere Maria Helena Martins, não terá condições de realizar o exercício da visão estética junto aos alunos, pois ele mesmo não a tem.

O trabalho dedicado à compreensão dos processos vividos pelo aluno como leitor, precisa, como contraparte, do investimento na afirmação da subjetividade do professor, em sua autoconfiança e autorização para conduzir o processo de ensino e aprendizagem com segurança em si mesmo, valorizando sua personalidade, inclusive 
como viabilizadora do aprendizado. $\mathrm{Na}$ comunidade escolar, ainda que não possua os mesmos laços afetivos de uma comunidade oral ou tradicional, o professor pode angariar, em alguma medida, o respeito dos alunos a partir de sua conduta, assim como um narrador com sua audiência. A importância desse aspecto na docência é algo, muitas vezes, ouvido de forma espontânea em relatos de experiência, ou em homenagens ao professor, mas ela pode também constituir matéria de reflexão e princípio teóricometodológico.

A personalidade do sujeito precisa fazer diferença no contexto em que atua. Retomamos, para finalizar, três casos tomados como exemplo de um processo que pode levar o professor a essa condição, dois deles já mencionados anteriormente. Paulo Freire, ao falar da importância do ato de ler, conta toda a sua história como leitor. A partir dela, certamente, toma mais consciência dos processos que o levaram a ser leitor, desde os mais elementares, anteriores à escrita. Tomando consciência desse processo é que ele ganha confiança para pensar em formas que possibilitem a outros a oportunidade, não de vivenciarem a mesma experiência, pois são sujeitos que ocupam lugares únicos na existência, mas de se apropriarem de suas sugestões, dialogar com ele, identificarem-se com ele, diferenciarem-se dele, até trilharem o próprio caminho de forma autônoma.

Outro exemplo dessa tomada de consciência de si é o de uma professora, registrado no livro Percursos de sentidos: de leitores a formadores de leitores, que reúne histórias de leitura de mestrandos do ProfLetras, dentre as quais destacamos o sentido de experiência vivenciado e de identificação, quando a leitora-autora depõe sobre o contato com a obra Olhai os lírios do campo, de Érico Veríssimo:

Foi exatamente no pior momento da minha vida que esse encontro inesperado aconteceu, Eugênio e eu, isso mesmo, o protagonista de Olhai os lírios do campo era a minha pessoa na versão masculina. [...] conforme as páginas avançavam, comecei a ler a minha vida, uma garota de origem humilde, que vai estudar em um colégio particular graças aos esforços da mãe que lavava roupa para fora, sem falar no fato de ele ter um irmão, pois eu também tinha uma irmã. Nossas histórias eram idênticas, os nossos sofrimentos os mesmos, éramos pobres e não suportávamos aquilo. Quando Eugênio relata o episódio em que ele encontra o pai na rua e não sabe o que fazer para que seus colegas abastados financeiramente não descubram que aquele é seu pai, lembrei-me das inúmeras vezes pelas quais passei por meu pai e, simplesmente, fingia que não o conhecia. Aquilo doía muito em mim, e assim como Eugênio, também amava meus pais, mas tinha raiva deles por ter nascido naquela família simples e sem recursos. Por que eu? Por que não alguém menos provido de inteligência? Alguém que não entendesse o que era ser pobre. Olhai os lírios do campo foi um divisor de águas na minha trajetória como ser humano. [...] Percebi que tudo dependia de mim, de como eu enxergava as coisas. [...] A partir daquele momento, tive a certeza de que queria ser professora, e professora de literatura, para que outras pessoas tivessem a oportunidade de se encontrar, de resolverem seus conflitos interiores, auxiliadas pelas obras literárias." (ZOCOLOTO, 2018, p. 41).

Note-se nitidamente o processo de experiência que vai do ético, com a identificação inicial com a personagem, ao estético, em que há transformação do ser professora e da forma como a professora passou a enxergar as coisas. O retorno a si é 
marcado, nesse relato, pela tomada de consciência de sua autonomia para agir e da responsabilidade sobre sua visão de mundo. Ainda que a experiência inicial tenha sido de sofrimento, o resultado é a autoconfiança a respeito da decisão de que "tudo dependia de mim."

Todorov, no livro $A$ literatura em perigo, realiza um exame das consequências das ideias que defendeu e promoveu, tendo a sensatez de reconhecer os rumos equivocados que o ensino de literatura tomou ao logo do tempo. Ele poderia ter se imiscuído de falar sobre o assunto, mas se julgou responsável, sendo um dos idealizadores da corrente, por tentar esclarecer as falhas e possibilidades do trabalho com o texto literário. Quando tomou essa decisão, chamou a atenção justamente para o caráter ético e humanizador da literatura. Todorov transmite sua experiência pessoal e única, não como uma imposição ou indicação de um dever de mudança, mas como conselho.

A partir de erros e acertos, os três autores compõem narrativas de suas próprias experiências, mais do que desenvolvem conceitos teóricos, para falar do ensino. Ressalta-se, em todos, a figura do professor, que, assim como o narrador em Benjamin (1994, p. 221), alcança o benefício de "poder contar sua vida."

\section{REFERÊNCIAS}

BAKHTIN, M. O autor e a personagem na atividade estética. In: BAKHTIN, M. Estética da criação verbal. Tradução de Paulo Bezerra. São Paulo: Martins Fontes, 2006.

BARBOSA, E. O narrador em Mikhail Bakhtin. In: Brandão, Luis Alberto (org.). Respostas a Bakhtin. Belo Horizonte: FALE/UFMG, 2012. (Edições Viva Voz).

BENJAMIN, W. O narrador: considerações sobre a obra de Nikolai Leskov. In: BENJAMIN, W. Magia e técnica, arte e política: ensaios sobre literatura e história da cultura. São Paulo: Brasiliense, 1994, p. 197-221.

CANDIDO, A. A literatura e a formação do homem. Remate de Males, Campinas, p.8190, 3 dez. 2012.

COLOMER, T. Andar entre libros. México, D.F.: Fondo de Cultura Económica, 2011. (ePub)

COSSON, R. Nós que ensinamos literatura. In: NAVAS, D.; CARDOSO, E.; BASTAZIN, V. (org.); Literatura e Ensino: territórios em diálogo. São Paulo: EDUC: Capes, 2018. (ePub)

. Letramento literário: teoria e prática. São Paulo: Contexto, 2014. (ePub)

FREIRE, P. A importância do ato de ler: em três artigos que se completam. São Paulo: Cortez Editora; Editora Autores Associados, 1989.

JOUVE, V. A leitura. São Paulo: Editora Unesp, 2002.

LARROSA, J. Tremores: escritos sobre experiencia. Tradução de Cristina Antunes e João Vanderlei Geraldi. Belo Horizonte: Autênteica, 2014. (Coleção Experiência e Sentido). MARTINS, M. H. O que é leitura. São Paulo: Brasiliense, 1988. (Coleção primeiros passos).

PACHECO, J. Dicionário de valores. São Paulo: Edições SM, 2012.

ROUXEL, A; LANGLADE, G; REZENDE, N (Orgs.). Leitura subjetiva e ensino de 


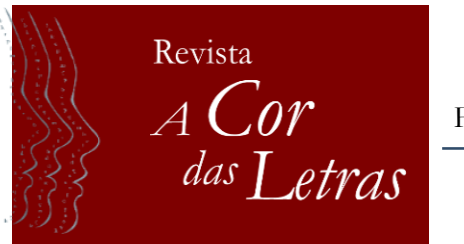

literatura. São Paulo: Alameda, 2013.

ROUXEL, A. Práticas de Leitura: quais rumos para favorecer a expressão do sujeitoleitor? em: Cadernos de pesquisa, V. 42, nº 145, p. 272-283. São Paulo: Fundação Carlos Chagas, 2012.

TODOROV, T. A literatura em perigo. Rio de Janeiro: DIFEL, 2009.

ZOCOLOTO, C. Experiências com a literatura na escola e na vida. Em: Per(cursos) de sentidos: de leitores a formadores de leitores. COCCO, M. H. (org.) Coleção Sala das Letras, Cuiabá: Carlini e Caniato Editorial e UNEMAT, 2018.

Recebido em: 28/10/2019

Aprovado em: 07/12/2019

Publicado em: 19/12/2019 